\title{
Relevância dos ativos intangíveis em empresas de alta e baixa tecnologia
}

Relevance of intangible assets in high and low companies technology

\author{
Cristian Baú Dal Magro \\ Universidade Regional de Blumenau \\ Alini da Silva \\ Universidade Regional de Blumenau \\ Daniel Padilha \\ Universidade Regional de Blumenau
}

Roberto Carlos Klann

Universidade Regional de Blumenau

\begin{abstract}
The literature on value relevance has consolidated that traditional accounting information influence investor decision-making, as the purchase or sale of shares. The implementation of IFRS has standardized intangible assets, which were previously not covered. Thus, this study aimed to analyze the relevance of intangible assets in high and low-tech companies. We conducted a descriptive, documentary and quantitative research. We used descriptive statistics and panel data analysis to analyze 2,228 US companies; and 118 companies in Brazil. The results showed that the equity and income adjusted for intangible accounts as well as intangible assets and goodwill are relevant value for economic agents, particularly for investors, impacting the stock price in the Brazilian and American markets. It is concluded that the relevance of intangible assets in technology companies influences the increase of the share price.
\end{abstract}

\section{Keywords}

value relevance; intangible assets; technology companies.

JEL Code M40.

\section{Resumo}

A literatura sobre value relevance tem consolidado que informações contábeis tradicionais influenciam na tomada de decisão de investidores, quanto à compra ou venda de ações. A implantação das IFRS normatizou os ativos intangiveis, que anteriormente não eram contemplados. Dessa forma o presente estudo teve como objetivo analisar a relevância dos ativos intangiveis em empresas de alta e baixa tecnologia. Realizou-se uma pesquisa descritiva, documental e quantitativa. Utilizou-se estatística descritiva e análise de dados em painel para analisar 2.228 empresas dos EUA; e 118 empresas do Brasil. Os resultados demonstraram que o patrimônio e o lucro ajustado por contas de intangiveis, bem como o ativo intangivel e o goodwill possuem relevância de valor para os agentes econômicos, principalmente para os investidores, impactando o preço das ações nos mercados brasileiro e americano. Conclui-se que a relevância dos ativos intangiveis nas empresas de tecnologia influencia no aumento do preço da ação.

\section{Palavras-chave}

value relevance; ativos intangiveis; empresas de tecnologia.

Código JEL M4O. 


\section{Introdução}

As diferentes abordagens em relação aos ativos intangíveis têm gerado inúmeros debates no campo teórico e dos negócios (Kayo, 2002). As constatações sobre ativos intangíveis e sua relevância no patrimônio das entidades são demonstradas em alguns estudos como os de Amir e Lev (1996), Edvinsson e Malone (1998), Hoegh-Krohn e Knivsfla (2000), Santos e Schmidt (2002), Kallapur e Kwan (2004), Goodwin e Ahmed (2006), Perez e Famá (2006), Oliveira, Rodrigues e Craig (2010), sendo decorrentes de alguns fatores, como na aquisição de empresas e na busca por bons resultados no ambiente em que se encontram inseridas.

Os ativos intangíveis correspondem a ativos não monetários identificáveis, os quais não possuem corpo físico e devem ser controlados pela empresa em decorrência de fatos passados que gerem benefícios econômicos futuros (IAS 38). O reconhecimento e a evidenciação dos ativos intangíveis têm grande utilidade principalmente nas empresas de tecnologia da informação, em que contribuem efetivamente para a formação de valor organizacional (Kayo, 2002).

O desenvolvimento do setor de tecnologia é importante no contexto econômico e social de qualquer país, porque as empresas que compõem esse segmento desenvolvem produtos e serviços com base em ideias inovadoras para atender às demandas do mercado (Weber; Klein, 2013). Nesse sentido, os administradores necessitam de inovação como meio de oportunidade para competir e obter rentabilidade nos negócios (Fleury; Fleury, 2004).

As evidências empíricas mostram que o declínio na relevância da informação contábil pode ter interferência do aumento da importância das indústrias tecnológicas. Tal alegação é justificada pelo fato de que nas empresas do ramo tecnológico as demonstrações financeiras, supostamente, não conseguem reconhecer alguns itens relevantes para a geração de fluxo de caixa futuro, podendo-se citar os gastos com pesquisa e desenvolvimento $(\mathrm{P} \& D)$ que configuram ativos intangíveis (Francis; Schipper, 1999).

A crescente diferença entre o valor contábil e de mercado das empresas tem influenciado o interesse de pesquisadores da contabilidade na mensuração e divulgação dos ativos intangíveis (Beattie, 2005). O conservadorismo nos critérios de reconhecimento dos ativos intangíveis e preocupações ligadas às normas contábeis contemporâneas têm gerado debates pelas divergências e falhas nas formas de reconhecimento. Portanto, as empre- 
sas que investem em ativos intangíveis possuem dificuldades em divulgar informações confiáveis aos seus usuários (Oliveira et al., 2010).

A relevância da informação contábil para o mercado de capitais, de acordo com Barth, Landsman e Lang (2008), refere-se ao impacto de uma informação contábil no preço das ações. $O$ preço das ações no mercado pode sofrer variação no momento em que agentes econômicos verificam informações publicadas em relatórios que anteriormente não conheciam. Assim, o conhecimento do resultado da empresa pelos agentes econômicos pode afetar a sua tomada de decisão (Beaver, 1968).

Neste contexto de relevância de ativos intangíveis para o mercado de capitais e a importância que os intangíveis possuem para as empresas de tecnologia, o presente estudo possui como problemática: qual a relevância dos ativos intangíveis em empresas de alta e baixa tecnologia? Para a resolução do problema de pesquisa, tem-se como objetivo analisar a relevância dos ativos intangíveis em empresas de alta e baixa tecnologia.

Estudos internacionais, como de Amir e Lev (1996), examinaram a relevância para os usuários, de informações financeiras e informações não financeiras (pesquisas e intangíveis) de empresas de telefonia celular independente dos EUA. Aboody e Lev (1998) examinaram a relevância de informações sobre a capitalização dos custos de desenvolvimento de softwares para investidores de empresas dos EUA. Francis e Schipper (1999) analisaram a relevância da informação contábil em empresas de alta tecnologia considerando as que investem em P\&D (intangível), e empresas de baixa tecnologia dos EUA. Kallapur e Kwan (2004) examinaram a relevância de valor e a confiabilidade dos ativos intangíveis em empresas do Reino Unido, constatando a existência de reação no preço das ações.

Goodwin e Ahmed (2006) examinaram a relevância no valor dos lucros em empresas australianas que reconheciam ativos intangíveis em suas demonstrações financeiras. Oliveira et al. (2010) analisaram a relevância de valor nos montantes de ativos intangíveis identificáveis e sobre o ágio relatado nas demonstrações contábeis de empresas não financeiras listadas na Bolsa de Valores de Portugal. Ciftci, Darrough e Mashruwala (2014) analisaram, em empresas tangíveis intensivas e intangíveis intensivas dos EUA, a utilidade de informações contábeis para os investidores.

Estudos nacionais, por sua vez, tais como os de Rezende (2005) e de Decker et al. (2013), verificaram outra conjectura sobre a relevância da informação de ativos intangíveis. Rezende (2005) analisou os efeitos dos 
investimentos (diferido, intangível) sobre o value relevance do lucro e do patrimônio líquido de empresas brasileiras pertencentes ao setor com alta concentração de intangíveis; empresas com baixa concentração de intangíveis em empresas do setor de bancos e seguros, entre 1995 e 2003. Por sua vez, Decker et al. (2013) analisaram a relação entre os ativos intangíveis e a rentabilidade de empresas brasileiras, no período de 2006 a 2011.

O presente estudo difere no aspecto em que busca explicar, especificamente, a relevância no valor dos ativos intangíveis, enquanto que a preocupação de Francis e Schipper (1999) foi verificar a perda da relevância no valor das informações contábeis ao longo do tempo. Rezende (2005) fez uma comparação de empresas brasileiras e americanas com relação à relevância do ativo intangível.

Então, a presente pesquisa justifica-se por trazer evidências empíricas, contribuindo com os estudos sobre o tema realizados em empresas da Austrália, Reino Unido, EUA, Portugal e Brasil. Este trabalho também buscou ampliar os resultados pela confrontação da relevância da informação sobre os intangíveis em empresas de um país emergente (Brasil) com empresas de um país desenvolvido (EUA), a fim de constatar efeitos provenientes de características econômicas. Complementarmente, buscou-se comparar as empresas de alta e baixa tecnologia de ambos os países.

O gap encontrado na literatura suporta a justificativa de análise das informações contábeis com padrões diferenciados de normatização, visto que a literatura sobre o tema, de maneira geral, observa os aspectos propostos com enfoque sobre um único padrão contábil. De acordo com esta inferência, a proposta contribui ao comparar informações contábeis de diferentes padrões de normatização, a fim de observar novos fatores explicativos para a relevância da informação sobre o impacto no preço e retorno das ações. Optou-se em analisar as empresas brasileiras em comparação com as empresas norte-americanas devido à utilização de diferentes padrões de normas contábeis, respectivamente IASB e FASB.

O estudo está estruturado primeiramente pela introdução; depois aborda-se no referencial teórico as principais referências acerca de value relevance de ativos intangíveis e também as referências sobre as características de empresas de alta tecnologia e sua relação com os ativos intangíveis. Em seguida, apresentam-se os procedimentos metodológicos, contemplando população e amostra, coleta e análise dos dados. Na sequência, tem-se a descrição e análise dos resultados e por fim as considerações finais. 


\section{Referêncial teórico}

\subsection{Value Relevance de ativos intangíveis}

Os propulsores da pesquisa contábil sobre mercado de capitais foram Ball e Brown (1968). Na época, relacionaram a informação contábil e o mercado de capitais, indicando que o anúncio de lucro agrega valor informativo para o mercado. Além disso, constataram que nem toda informação é completamente antecipada pelo mercado, e existe a tendência de movimento que persiste após os anúncios da contabilidade.

Posteriormente, o estudo de Beaver, Clarke e Wright (1979) analisou a relação entre a magnitude na variação dos lucros e a variação dos retornos. Concluíram que existe relação direta entre o percentual de lucros anormais e a média anual de retornos anormais. Os estudos foram relevantes para a evolução dos conceitos relacionados à relevância da informação contábil sobre o preço e o retorno das ações.

A estrutura conceitual proposta por Ohlson (1995) é a base utilizada para expressar o poder explanatório dos preços como uma função do lucro e do patrimônio líquido reportado pelas organizações. O modelo demonstra que os números contábeis sobre a performance econômica e financeira das empresas são variáveis significativas para a avaliação e previsão no preço e retorno das ações.

Diante do exposto, o valor contábil é definido como relevante se tiver associação prevista com os valores de mercado, e quando for capaz de apresentar diferenciais para as decisões de usuários (Barth, Beaver \& Landsman, 2001). Collins, Maydew e Weiss (1997) sugerem que o aumento na importância da prestação de serviços com alta agregação de tecnologia empregada, e de empresas com altos investimentos em ativos intangíveis, tem contribuído para as mudanças na relevância da informação contábil ao longo dos últimos tempos.

No período anterior à harmonização das normas internacionais de contabilidade, informações sobre ativos intangíveis não eram obrigatórias para empresas de alguns países. Nesta época, Amir e Lev (1996) e Lev (1997) indicavam que as informações sobre ativos intangíveis eram limitadas para avaliação das empresas do setor de tecnologia e serviços, e o lucro líquido e o patrimônio líquido eram irrelevantes para determinar o valor das companhias com alta concentração de intangíveis. Para Collins 
et al. (1997), não era possível predizer como o tratamento contábil dos intangíveis poderia afetar a importância do lucro e do patrimônio líquido.

A ampla adoção de novas tecnologias de informação tem elevado a importância do ativo intangível na determinação do valor corporativo (Lev, 2001). Sendo assim, muitas questões têm sido levantadas sobre a relevância no valor das medidas contábeis que surgem na contabilização de ativos intangíveis (Francis; Schipper, 1999; Lev; Zarowin, 1999; Lev, 2001).

Para Aboody e Lev (1998), o registro dos ativos intangíveis resume e oferece informações relevantes para os investidores, e a não capitalização está associada a largos erros na previsão dos analistas de mercado.

Logo, com a obrigatoriedade de harmonização das normas internacionais de contabilidade em diversos países, a pesquisa sobre a relevância da informação contábil, considerando os aspectos relacionados à divulgação dos ativos intangíveis, tem ganhado destaque. Oliveira et al. (2010) abordaram questões sobre a relevância de valor dos dados contábeis, concentrando-se em ativos intangíveis reconhecidos e em implicações da adoção formal de IAS e IFRS. A adoção das IAS e das IFRS tem sido amplamente aceita por países da União Europeia, América Latina, Ásia e Oceania, com o objetivo de melhorar a transparência e a comparabilidade das demonstrações financeiras por parte das empresas e dos usuários dessas informações no âmbito mundial (Baker; Barbu, 2007).

Por outro lado, as IFRS não são utilizadas para o estabelecimento e regulamentação das práticas de contabilidade em empresas dos EUA. A Financial Accounting Standards Board (FASB) é o órgão de normatização das práticas de contabilidade para as empresas dos EUA. Apesar da convergência das normas de contabilidade, as diferenças continuarão a existir entre os US GAAP e as IFRS (Ernest \&Young, 2011).

É preciso inferir que os dois conjuntos de normas, geralmente, são mais parecidos do que diferentes para transações mais comumente encontradas, com as IFRS sendo, em grande parte, os mesmos princípios básicos que os US GAAP. Os princípios gerais e o quadro conceitual são muitas vezes semelhantes em ambos os conjuntos de normas, levando a resultados contábeis similares. A existência de eventuais diferenças e a sua materialidade para as demonstrações contábeis depende de uma variedade de fatores específicos, incluindo a natureza da entidade, o detalhe das operações, a interpretação dos princípios, entre outros fatores (Ernest \& Young, 2011). 
O reconhecimento de um ativo intangível é realizado atendendo sua definição e mensuração confiável, a fim de compor valor preciso. Tal reconhecimento é semelhante aos requisitos dos ativos tangíveis, o que pode dificultar sua avaliação (Hendriksen; Van Breda, 1999). Os ativos intangíveis são definidos pelo Pronunciamento Técnico CPC 04 R1 como um ativo não monetário e sem substância física. $\mathrm{O}$ seu reconhecimento pela contabilidade deve atender à característica de ser identificado como intangível, ser controlado pela empresa e gerar benefício econômico futuro para esta.

O reconhecimento, a mensuração e o estabelecimento de normas nacionais e internacionais desencadearam um aumento de trabalhos empíricos com o objetivo de analisar o value relevance de contas contábeis tradicionais, com o propósito de mensurar o uso da informação financeira pelos investidores (Oliveira et al., 2010). A justificativa para esse interesse reside na análise de informações divulgadas, por meio dos números contábeis, com capacidade de auxiliar investidores na tomada de decisão (Dumontier; Raffournier, 2002). Além disso, nas duas últimas décadas, o aumento da concorrência empresarial e o desenvolvimento de novas tecnologias de informação têm originado maior relevância dos ativos intangíveis, colocando-os como um dos principais propulsores do valor corporativo (Lev, 2001).

Diversas pesquisas nacionais e internacionais analisaram a relação entre ativos intangíveis e a relevância de seu valor no mercado por meio do seu impacto no preço das ações. Amir e Lev (1996) examinaram a relevância de informações financeiras (lucro, valores contábeis e fluxos de caixa) e informações não financeiras (pesquisas e intangíveis) de empresas de telefonia celular independente norte americanas para os investidores. Os achados apontaram que as informações financeiras eram irrelevantes para a avaliação das empresas no mercado de capitais. Contudo, quando combinadas as informações financeiras com informações não financeiras e ajustes dos intangíveis, algumas das variáveis analisadas contribuíram para explicar o preço das ações. Dessa forma, sugeriu-se que informações não financeiras em empresas com alto crescimento (de telefonia celular) contribuem, em maior proporção, para a tomada de decisão de usuários externos, do que informações como lucro, valores contábeis e fluxo de caixa.

Aboody e Lev (1998) pesquisaram a relevância de informações sobre a capitalização dos custos de desenvolvimento de software (componen- 
te do custo de pesquisa e desenvolvimento - ativo intangível) para os investidores. Foram analisadas empresas dos EUA, no período de 1987 a 1995. Os resultados demonstraram que o valor dos custos de desenvolvimento de software e sua amortização apresentaram relação significativa com variáveis do mercado de capitais e ganhos futuros. Concluiu-se, então, que a capitalização de software apresenta informações relevantes aos usuários externos, como investidores, influenciando suas decisões e o preço das ações.

Lopes (2002) forneceu evidências de que a relevância da informação contábil em empresas da nova economia (telecomunicações) foi de melhor poder explicativo, em relação às empresas da antiga economia (siderúrgicas, têxteis, metalurgia, mecânica industrial, química, processamento de minério e petroquímica), o que está atrelado ao reconhecimento de ativos intangíveis pelas empresas da nova economia.

Rezende (2005) analisou os efeitos dos investimentos (diferido, intangível) sobre o value relevance do lucro e patrimônio líquido de empresas brasileiras pertencentes ao setor de telecomunicações (alta concentração de intangíveis); empresas siderúrgicas (baixa concentração de intangíveis) e empresas do setor de bancos e seguros. O período de análise compreendeu os anos de 1995 a 2003. Os achados evidenciaram que o lucro líquido e o patrimônio líquido das empresas analisadas apresentaram relação significativa com o preço das ações. No entanto, o ativo intangível apresentou baixo poder explicativo e efeito redutor do preço das ações nos três setores analisados.

Oliveira et al. (2010) analisaram a relevância de valor dos montantes de ativos intangíveis identificáveis e do ágio relatados nas demonstrações contábeis de empresas não financeiras listadas na Bolsa de Valores de Portugal, no período de 1998 a 2008. Os achados demonstraram que o ágio, outros ativos intangíveis e o lucro líquido estavam relacionados significativamente com o preço das ações. Também verificaram que a adoção das IFRS não impactou na relevância dos ativos intangíveis. De modo geral, observou-se que o ativo intangível é uma informação relevante para os usuários das demonstrações financeiras.

Silva, Souza e Klann (2015) analisaram a influência dos ativos intangíveis na relevância das informações contábeis de empresas brasileiras no período de 2010 a 2013. Os achados evidenciaram que o reconhecimento de ativos intangíveis impacta a tomada de decisão de investidores quanto 
à compra e venda de ações, e inclusive melhora a relevância de informações contábeis, tais como: patrimônio e lucro líquido. Inferiram sobre a importância do reconhecimento e evidenciação de ativos intangíveis pelas empresas, a fim de criar valor para as empresas no mercado e diminuir a assimetria da informação em relação aos usuários externos.

\subsection{Características de empresas de alta tecnologia e sua relação com os ativos intangíveis}

O desenvolvimento de novas tecnologias pode ocorrer em ambientes propícios a esta condição, como no campo de bens de capital, onde são produzidos eletrônicos e materiais de telecomunicação e em que a inovação é fator essencial para bons resultados no mercado (Barras, 1986). As firmas buscam inovar em decorrência das mudanças tecnológicas e gerenciais e em função da concorrência do ambiente em que estão inseridas e da busca dos administradores por melhores níveis de desempenho (Damanpour; Walker; Avellaneda, 2009).

Após a globalização, os campos de atuação das empresas foram sendo abertos e as fronteiras desse alcance diminuindo (Lastres et al., 1998). Nesse sentido, essa nova fase desencadeou uma forte concorrência empresarial, acelerando a adoção de novas tecnologias nos processos de produção e comunicação, além da exigência para o desenvolvimento de um novo método de administrar os recursos (Cassiolato, 1999).

O uso intensivo das tecnologias resulta em maior flexibilidade nos processos produtivos e maior eficiência no uso dos recursos (Takahashi, 2000). Assim, Albertin (2001) menciona que a tecnologia é fator essencial para a otimização dos resultados da empresa, sendo considerado um artefato que transforma o sistema de operações da firma, a produção, as relações organizacionais e a concorrência, sua implantação significando um desafio que exige planejamento adequado.

Nesse sentido, é importante observar a classificação de empresas consideradas como de alta e ou baixa tecnologia. De acordo com a OCDE (2003), os setores com alta tecnologia são: aeroespacial, farmacêutico, informática, eletrônica e telecomunicação. Por outro lado, os setores com baixa tecnologia são: reciclagem, madeira, papel e celulose, editorial e gráfica, alimentos, bebidas e fumo, têxtil, confecções, couro e calçados. 
As empresas com capital aberto são classificadas em setores pela BM\&FBovespa de acordo com a análise dos produtos ou serviços que mais contribuem para a formação das receitas das companhias. Como empresas de alta tecnologia, de acordo com a OCDE (2003), a bolsa de valores possui somente os setores de tecnologia e telecomunicações em que enquadram-se no setor de tecnologia as empresas que vendem computadores e equipamentos e as empresas que fazem programas e serviços, já as empresas do setor de telecomunicações prestam serviço de telefonia fixa e telefonia móvel.

$\mathrm{O}$ investimento em tecnologia pode ocasionar riscos maiores em relação ao investimento em capital, pois seus elementos são considerados frágeis, sujeitos à sabotagem e descentralizados (Schniederjans; Hamaker; Schniederjans, 2004). No entanto, a tecnologia desencadeou mudanças nos métodos de gerenciamento dos negócios e sua implantação gerou novas características para o setor de Tecnologia da Informação (TI), desenvolvendo uma economia com base digital e tornando o conhecimento fator fundamental para o sucesso empresarial. Anteriormente à adoção de um novo método tecnológico operacional e ou administrativo, faz-se necessário uma avaliação, observando o retorno financeiro de tal investimento (Huang et al., 2006).

Evidências empíricas com relação à tecnologia mostram efeitos positivos quanto à produção e ao crescimento econômico dos países em desenvolvimento. Entretanto, nesses países, esse relacionamento é pouco investigado (Hamdan; Kasper, 2010), com investigações precoces sobre inovação. Além disso, Damanpour e Aravind (2012) mencionam sobre a necessidade das organizações manterem atenção sobre os investimentos em inovação e tecnologia.

Diante das discussões sobre tecnologia, infere-se de maneira conceitual sua definição. De acordo com Marcovitch, Santos e Dutra (1986) e Ferro e Torkomian (1988), as empresas de tecnologia são aquelas que possuem à disposição produtos ou processos que incorporam elevado conteúdo tecnológico e científico. Complementarmente, Carvalho et al. (1998) descrevem que o desenvolvimento de produtos e processos não é a única característica das empresas com tecnologia, também é preciso que contemplem aplicações sistemáticas de conhecimento técnico-científico em seus processos operacionais.

Quanto aos estudos nacionais e internacionais que abordaram a importância e relação entre ativos intangíveis (de forma geral) em empresas de 
baixa ou alta tecnologia, têm-se o estudo de Sonnier (2008), Reina et al. (2011), Vafaei, Taylor e Ahmed (2011), Liao, Chan e Seng (2013).

Sonnier (2008) realizou uma análise de conteúdo com base nos relatórios anuais de empresas dos Estados Unidos, sendo 143 de alta tecnologia e 141 do setor tradicional. Os resultados indicaram que as empresas de alta tecnologia divulgam com maior consistência as informações sobre ativos intangíveis relacionados ao capital organizacional, capital humano e propriedade intelectual. Portanto, as empresas americanas de alta tecnologia têm um maior nível de divulgação dos ativos intangíveis do que as empresas do setor tradicional.

Reina et al. (2011) analisaram a evidenciação voluntária de ativos intangíveis, especificamente capital intelectual, em empresas brasileiras do setor de tecnologia da informação e telecomunicação. Os achados evidenciaram que antes da obrigatoriedade das IFRS pelas empresas brasileiras, aquelas do setor de tecnologia e telecomunicação já evidenciavam de maneira voluntária informações acerca de ativos intangíveis relacionados ao capital intelectual de seus colaboradores. Desse modo, concluíram que $92 \%$ das empresas do setor de telecomunicação evidenciaram elementos de capital intelectual em 2007, e 78\% das empresas do setor de tecnologia da informação evidenciaram tais elementos em 2007, elevando esse número para 87,5\% entre os anos de 2008 e 2009.

Vafaei et al. (2011) testaram o grau de relevância de valor de informações contábeis para o mercado de capitais após a adoção das IFRS em alguns países da Europa. Entre os achados, os autores observaram que informações tais como intangível e goodwill foram impactadas pela adoção das IFRS e que impactaram o mercado de capitais principalmente para as empresas listadas em segmentos não tradicionais, como o de tecnologia.

Liao et al. (2013) verificaram após a adoção das IFRS se empresas de alta tecnologia do Reino Unido tiveram um aumento no nível de disclosure de capital intelectual (ativo intangível). Os resultados evidenciaram que as empresas do setor de alta tecnologia após a adoção das IFRS, realmente divulgaram em maior nível de informações quanto ao capital intelectual, principalmente as empresas mais antigas no mercado. Inferiram também que a adoção das IFRS auxilia no aumento da vantagem competitiva das empresas pela gestão de ativos como capital intelectual, que possuem cunho estratégico para as empresas. 


\section{Procedimentos metodológicos}

A presente pesquisa, que tem como objetivo analisar a relevância dos ativos intangíveis em empresas de alta e baixa tecnologia configura-se como descritiva. Em relação aos procedimentos, enquadra-se como documental, pois foram utilizados dados coletados das demonstrações contábeis das empresas investigadas, além de informações disponibilizadas em base de dados. Em relação à abordagem do problema, o estudo é classificado como quantitativo, pois analisa um número relativamente significativo de observações, com apoio de instrumentos estatísticos.

\subsection{População e amostra}

A população do estudo compreendeu todas as empresas listadas na Bolsa de Valores Mercadorias e Futuros de São Paulo - BM\&FBOVESPA (457 empresas) e da New York Stock Exchange - NYSE (12.514 empresas). A amostra da pesquisa correspondeu a 1.884 empresas de baixa tecnologia e 344 empresas de alta tecnologia dos EUA; 113 empresas de baixa tecnologia e 5 empresas de alta tecnologia do Brasil. A amostra do estudo foi delimitada pelas empresas que apresentavam todas as informações em relação às variáveis e aos períodos analisados. Os dados foram coletados trimestralmente, no período compreendido entre os anos de 2010 a 2013.

O período de análise foi delimitado entre o ano de 2010 a 2013 devido à utilização das IFRS obrigatoriamente pelas empresas brasileiras a partir do exercício de 2010. Desta forma, não se incluiu período anterior para não distorcer as informações que remetem à relevância das informações contábeis, visto que anterior a 2010 não havia obrigação de utilização de tais normas. Também utilizaram-se informações após o período da crise internacional ocorrida em 2008, visto que poderiam repercutir em discrepâncias na cotação das ações, cujos efeitos se prolongariam ao longo do exercício de 2009. De maneira geral, justifica-se que as escolhas buscaram mitigar efeitos da normatização contábil no reconhecimento de ativos intangíveis e da crise financeira internacional.

Consideraram-se empresas de alta tecnologia as dos setores de tecnologia da informação e telecomunicações, de acordo com a classificação da OCDE (2003). E as empresas de baixa tecnologia como materiais bá- 
sicos, bens de consumo, serviços ao consumidor, financeiro, cuidados de saúde, industriais e de utilidades também classificadas de acordo com OCDE (2003).

Optou-se por esta amostra ao considerar que a NYSE gerencia ações de empresas localizadas principalmente nos EUA, país desenvolvido, e que adotam normas contábeis em US GAAP - FASB. Por outro lado, as empresas listadas na BM\&FBOVESPA operam suas atividades essencialmente no Brasil, país emergente, e adotam normas contábeis em IFRS - IASB.

Assim, a seleção da amostra possibilita comparar a influência dos ativos intangíveis na relevância da informação contábil entre empresas de baixa tecnologia e alta tecnologia, considerando também o mercado em que essas empresas operam (emergente ou desenvolvido) e as normas contábeis adotadas (US GAAP ou IFRS).

\subsection{Coleta e análise dos dados}

A coleta dos dados foi realizada por meio do sítio eletrônico da Thomson ONE Banker, nas bases de dados Thomson Financial, Worldscope e Compustat. Foram coletadas informações trimestrais referentes ao preço das ações, quantidade de ações, patrimônio líquido, lucro líquido, ativo intangível, goodwill, despesas de amortização e perdas de impairment. Em relação à coleta da variável preço da ação, cabe salientar que esta foi ajustada aos dividendos, splits e outros eventos. $\bigcirc$ Quadro 1 demonstra as variáveis utilizadas no estudo.

Quadro 1 Variáveis da pesquisa

\begin{tabular}{l|l|l}
\hline Variável & Descrição & Autores \\
\hline \multicolumn{1}{l|}{ Variáveis dependentes } & \multicolumn{2}{l}{} \\
\hline $\mathbf{P}_{\text {it+3 }}$ & $\begin{array}{l}\text { Preço das ações da empresa três meses após o final do } \\
\text { trimestre. }\end{array}$ & Oliveira et al. (2010) \\
\hline $\mathbf{P}_{\text {it+6 }}$ & $\begin{array}{l}\text { Preço das ações da empresa seis meses após o final do } \\
\text { trimestre. }\end{array}$ & $\begin{array}{l}\text { Adaptado de Oliveira et al. } \\
(2010)\end{array}$ \\
\hline $\mathbf{R}_{\mathrm{it}+3}$ & $\begin{array}{l}\text { Logaritmo Natural do Retorno da ação da empresa três } \\
\text { meses após o final do trimestre }\end{array}$ & $\begin{array}{l}\text { Adaptado de Ball e Brown } \\
(1968)\end{array}$ \\
\hline $\mathbf{R}_{\mathrm{it}+6}$ & $\begin{array}{l}\text { Logaritmo Natural do Retorno da ação da empresa seis } \\
\text { meses após o final do trimestre. }\end{array}$ & $\begin{array}{l}\text { Adaptado de Ball e Brown } \\
(1968)\end{array}$ \\
\hline
\end{tabular}

(continua) 
Quadro 1 (continuação)

\begin{tabular}{|c|c|c|}
\hline Variável & Descrição & Autores \\
\hline \multicolumn{3}{|c|}{ Variáveis independentes } \\
\hline PL-Al & $\begin{array}{l}\text { Valor contábil do patrimônio líquido menos o valor dos } \\
\text { ativos intangíveis (Al) reconhecidos (incluindo goodwill), } \\
\text { dividido pela quantidade de ações da empresa. }\end{array}$ & Oliveira et al. (2010) \\
\hline LL-Al & $\begin{array}{l}\text { Valor contábil do lucro líquido menos as despesas de } \\
\text { amortização e as perdas por impairment dos ativos } \\
\text { intangíveis (Al), dividido pela quantidade de ações da } \\
\text { empresa. }\end{array}$ & Morricone et al. (2009) \\
\hline Al & Ativos intangíveis identificáveis por ação. & $\begin{array}{l}\text { Morricone et al. (2009), } \\
\text { Oliveira et al. (2010) }\end{array}$ \\
\hline GOOD & Goodwill por ação. & $\begin{array}{l}\text { Morricone et al. (2009), } \\
\text { Oliveira et al. (2010) }\end{array}$ \\
\hline $\begin{array}{l}\text { Dummy } \\
\text { Tecn }\end{array}$ & $\begin{array}{l}\text { Variável Dummy igual a } 1 \text { para as empresas com alta } \\
\text { tecnologia (setor de tecnologia e telecomunicações), } \\
\text { e } 0 \text { para as empresas com baixa tecnologia (demais } \\
\text { setores) }\end{array}$ & \multirow[t]{4}{*}{$\begin{array}{l}\text { Elaboração própria de } \\
\text { variáveis para testes } \\
\text { adicionais. }\end{array}$} \\
\hline $\begin{array}{l}\text { Dummy } \\
\text { Tecn*Al }\end{array}$ & $\begin{array}{l}\text { Interação entre a variável Dummytecn e a variável AI, } \\
\text { por meio de multiplicação de ambas. }\end{array}$ & \\
\hline $\begin{array}{l}\text { Dummy } \\
\text { Tecn*GOOD }\end{array}$ & $\begin{array}{l}\text { Interação entre a variável Dummytecn e a variável } \\
\text { GOOD, por meio de multiplicação de ambas. }\end{array}$ & \\
\hline $\begin{array}{l}\text { Dummy } \\
\text { Pais }\end{array}$ & $\begin{array}{l}\text { Variável Dummy igual a } 1 \text { para as empresas do Brasil, } \\
\text { e } 0 \text { para as empresas dos EUA. }\end{array}$ & \\
\hline
\end{tabular}

Fonte: Dados da pesquisa.

De acordo com o Quadro 1, foram formuladas 8 equações para regressões de dados em painel, baseadas nos modelos de Oliveira et al. (2010) para o preço da ação, e Ball e Brown (1968) para o retorno da ação. A primeira equação analisa a influência do patrimônio líquido ajustado (PL-AI), lucro líquido ajustado (LL-AI), ativo intangível (AI) e goodwill (GOOD) no preço das ações três meses após o término do trimestre anterior $\left(\mathrm{P}_{\mathrm{it+3} 3}\right)$, e a segunda equação testa a influência das variáveis explicativas no preço das ações seis meses após o término do trimestre anterior $\left(\mathrm{P}_{\mathrm{it}+6}\right)$.

$$
\begin{aligned}
& P_{i t+3}=b_{0}+b_{1} P L-A I_{i t}+b_{2} L L-A I_{i t}+b_{3} A I_{i t}+b_{4} G O O D_{i t}+e_{i t} \\
& P_{i t+6}=b_{0}+b_{1} P L-A I_{i t}+b_{2} L L-A I_{i t}+b_{3} A I_{i t}+b_{4} G O O D_{i t}+e_{i t}
\end{aligned}
$$

A terceira equação analisa a influência do patrimônio líquido ajustado (PL- 
-AI), lucro líquido ajustado (LL-AI), ativo intangível (AI) e goodwill (GOOD) no retorno das ações três meses após o término do trimestre anterior $\left(\mathrm{P}_{\mathrm{it}+3}\right)$, e a quarta equação testa a influência das variáveis explicativas no retorno das ações seis meses após o término do trimestre anterior $\left(\mathrm{P}_{\mathrm{it}+6}\right)$.

$$
\begin{aligned}
& R_{i t+3}=b_{0}+b_{1} P L-A I_{i t}+b_{2} L L-A I_{i t}+b_{3} A I_{i t}+b_{4} G O O D_{i t}+e_{i t} \\
& R_{i t+6}=b_{0}+b_{1} P L-A I_{i t}+b_{2} L L-A I_{i t}+b_{3} A I_{i t}+b_{4} G O O D_{i t}+e_{i t}
\end{aligned}
$$

Preliminarmente, para a análise dos dados foram aplicadas as quatro equações anteriores (1, 2, 3 e 4) nas empresas segregadas em alta tecnologia e baixa tecnologia, bem como pela separação das amostras de acordo com o país (Brasil; EUA).

Adicionalmente, foram elaboradas as equações cinco (5), seis (6), sete (7) e oito (8), as quais tiveram o propósito de atestar os achados preliminares, porém não se separaram a amostra em alta e baixa tecnologia e por país, ou seja, são modelos globais que incluíram todas as amostras de forma conjunta, incrementando variáveis dummys para capturar os efeitos das empresas de alta e baixa tecnologia,do país, e também variáveis de interação da tecnologia com ativo intangível e goodwill, respectivamente sobre o preço e retorno das ações.

$$
\begin{aligned}
& P_{i t+3}=b_{0}+b_{1} P L-A I_{i t}+b_{2} L L-A I_{i t}+b_{3} A I_{i t}+b_{4} G O O D_{i t}+ \\
& b_{5} \text { DummyTecn }+b_{6} \text { DummyTecn* } A I+b_{7} \text { DummyTecn } * G O O D+ \\
& b_{8} \text { DummyPaís }+e_{i t} \\
& P_{i t+6}=b_{0}+b_{1} P L-A I_{i t}+b_{2} L L-A I_{i t}+b_{3} A I_{i t}+b_{4} G O O D_{i t}+ \\
& b_{5} \text { DummyTecn }+b_{6} \text { DummyTecn* AI }+b_{7} \text { DummyTen * GOOD + } \\
& b_{8} \text { DummyPaís }+e_{i t} \\
& R_{i t+3}=b_{0}+b_{1} P L-A I_{i t}+b_{2} L L-A I_{i t}+b_{3} A I_{i t}+b_{4} G O O D_{i t}+ \\
& b_{5} \text { DummyTecn }+b_{6} \text { DummyTecn* AI }+b_{7} \text { DummyTecn*GOOD + } \\
& b_{8} \text { DummyPaís }+e_{i t} \\
& R_{i t+6}=b_{0}+b_{1} P L-A I_{i t}+b_{2} L L-A I_{i t}+b_{3} A I_{i t}+b_{4} G O O D_{i t}+ \\
& b_{5} \text { DummyTecn }+b_{6} \text { DummyTeen* AI }+b_{7} \text { DummyTen } * \text { GOOD + } \\
& b_{8} \text { DummyPaís }+e_{i t}
\end{aligned}
$$


Para a análise dos dados, foram utilizadas as técnicas estatísticas: estatística descritiva e análise de dados em painel, por meio dos softwares SPSS ${ }^{\circledR}$ e STATA®, respectivamente.

\section{Descrição e análise dos resultados}

Antes de analisar o efeito do ativo intangível na relevância da informação contábil de empresas de baixa e alta tecnologia brasileiras e americanas, por meio da regressão de dados em painel, faz-se uma análise relativa à estatística descritiva das variáveis em análise, conforme apresentado na Tabela 1.

Observa-se na Tabela 1 que a média no preço das ações das empresas de baixa tecnologia dos EUA (58,97 e 62,13 reais) é maior que nas empresas de baixa tecnologia do Brasil (21,12 e 21,15 reais). Achados similares foram encontrados com relação ao preço das ações nas empresas de alta tecnologia dos EUA, em comparação com empresas de alta tecnologia do Brasil. Por consequência, o retorno da ação também se demonstrou menor para empresas brasileiras de baixa e alta tecnologia, em comparação com as empresas de baixa e alta tecnologia dos EUA.

Em relação à média dos ativos intangíveis identificáveis por ação, verificou-se que nas empresas de baixa tecnologia dos EUA (14,41 reais) essa média é maior que nas empresas de baixa tecnologia do Brasil (12,01 reais). Por outro lado, a média dos ativos intangíveis identificáveis das empresas de alta tecnologia do Brasil (9,69 reais) é maior que nas empresas de alta tecnologia dos EUA (8,15 reais). Além disso, tem-se maior média de ativos intangíveis identificáveis para as empresas de baixa tecnologia em relação às empresas de alta tecnologia.

Por fim, demonstra-se que a média de goodwill das empresas de baixa tecnologia do Brasil (0,27 reais) é maior que a das empresas de baixa tecnologia dos EUA (-17,16 reais). Contudo, a média do goodwill das empresas de alta tecnologia dos EUA (21,10 reais) é maior que das empresas de alta tecnologia do Brasil (-4,69 reais). Em relação ao goodwill por ação de empresas com saldo negativo, isto deve-se pela perda de valor de mercado das empresas, visto que foi observado, pela diferença da multiplicação da quantidade de ações e preço das ações com o valor do patrimônio líquido. 
Tabela 1 Análise descritiva das variáveis dos modelos

\begin{tabular}{|c|c|c|c|c|c|c|}
\hline & País & Variáveis & Média & Desvio-Padrão & Mínimo & Máximo \\
\hline \multirow{16}{*}{ 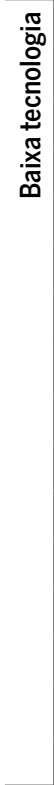 } & \multirow[t]{8}{*}{ EUA } & $P_{i t+3}$ & 58,970 & 49,078 & 0,014 & $6.511,540$ \\
\hline & & $P_{i t+6}$ & 62,131 & 51,972 & 0,013 & $6.740,040$ \\
\hline & & $\mathrm{R}_{\mathrm{it}+3}$ & 1,079 & 0,882 & 0,028 & 121,00 \\
\hline & & $\mathrm{R}_{\mathrm{it}+6}$ & 1,077 & 0,882 & 0,012 & 121,00 \\
\hline & & PL-Al ${ }_{\text {it }}$ & 75,242 & 186,163 & $-11.910,870$ & $170.618,205$ \\
\hline & & $\mathrm{LL}^{-A I_{i t}}$ & 4,448 & 10,590 & $-7.933,929$ & $8.091,114$ \\
\hline & & $A I_{i t}$ & 14,412 & 15,556 & $-0,398$ & $1.956,429$ \\
\hline & & $\mathrm{GOOD}_{\text {it }}$ & $-17,156$ & 91,723 & $-85.449,386$ & $8.616,656$ \\
\hline & \multirow[t]{8}{*}{ Brasil } & $P_{i t+3}$ & 21,119 & 13,770 & 0,018 & 396,310 \\
\hline & & $P_{i t+6}$ & 21,151 & 13,780 & 0,013 & 396,310 \\
\hline & & $\mathrm{R}_{\mathrm{it}+3}$ & 1,009 & 0,1741 & 0,341 & 2,8500 \\
\hline & & $\mathrm{R}_{\mathrm{it}+6}$ & 1,002 & 0,1722 & 0,341 & 2,8500 \\
\hline & & PL-Al ${ }_{\text {it }}$ & 8,576 & 28,065 & $-1091,315$ & 361,404 \\
\hline & & $L L-A I_{i t}$ & 4,056 & 7,262 & $-344,790$ & 507,002 \\
\hline & & $\mathrm{Al}_{\mathrm{it}}$ & 12,010 & 17,123 & 0,000 & $1.096,000$ \\
\hline & & $\mathrm{GOOD}_{\text {it }}$ & 0,273 & 15,502 & $-218,011$ & 161,877 \\
\hline \multirow{16}{*}{ 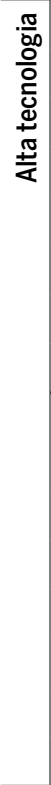 } & \multirow{8}{*}{ EUA } & $P_{i t+3}$ & 40,100 & 33,085 & 0,014 & $1.316,740$ \\
\hline & & $\mathrm{P}_{\mathrm{it}+6}$ & 42,127 & 35,058 & 0,014 & $1.316,740$ \\
\hline & & $\mathrm{R}_{\mathrm{it}+3}$ & 1,069 & 0,299 & 0,195 & 12,809 \\
\hline & & $\mathrm{R}_{\mathrm{it}+6}$ & 1,063 & 0,299 & 0,184 & 12,809 \\
\hline & & PL-Al ${ }_{\text {it }}$ & $-18,115$ & 27,695 & $-3239,620$ & 222,764 \\
\hline & & LL-AI $I_{\text {it }}$ & 1,381 & 3,733 & $-450,000$ & 738,861 \\
\hline & & $\mathrm{Al}_{\mathrm{it}}$ & 8,147 & 8,560 & 0,000 & 149,075 \\
\hline & & $\mathrm{GOOD}_{\text {it }}$ & 24,100 & 25,782 & $-107,237$ & $1.699,620$ \\
\hline & \multirow[t]{8}{*}{ Brasil } & $P_{i t+3}$ & 16,229 & 12,263 & 2,430 & 56,490 \\
\hline & & $\mathrm{P}_{\mathrm{it}+6}$ & 16,237 & 12,510 & 2,010 & 56,490 \\
\hline & & $\mathrm{R}_{\mathrm{it}+3}$ & 0,974 & 0,150 & 0,567 & 1,379 \\
\hline & & $R_{i t+6}$ & 0,984 & 0,207 & 0,567 & 2,156 \\
\hline & & PL-Al $\mathrm{it}_{\mathrm{it}}$ & 16,191 & 11,021 & $-6,236$ & 73,284 \\
\hline & & $L L-A I_{i t}$ & 4,432 & 5,361 & $-1,389$ & 112,622 \\
\hline & & $\mathrm{Al}_{\mathrm{it}}$ & 9,697 & 10,053 & 0,792 & 47,229 \\
\hline & & $\mathrm{GOOD}_{\text {it }}$ & $-4,698$ & 6,215 & $-51,091$ & 11,617 \\
\hline
\end{tabular}

Fonte: Dados da pesquisa. 
Para aplicar os modelos de regressão de dados em painel aos dados analisados, foi preciso testar os pressupostos da análise multivariada. Primeiramente, foi elaborado o teste de aleatoriedade e os resultados demonstraram que inexiste autocorrelação de primeira ordem entre os resíduos das variáveis aplicáveis aos modelos. Em seguida, foi elaborado o teste de normalidade, indicando que a distribuição dos resíduos é normal. Por fim, foi elaborado o teste de homoscedasticidade, verificando-se que a variância dos erros é uniforme.

Além disso, o estudo buscou atender aos procedimentos de Fama e Macbeth (1973), os quais estabelecem um processo para estimação apropriada em estudos de apreçamento. Este processo estima a correlação serial entre os erros de estimação das variáveis do estudo distribuídos anualmente, demonstrando se o modelo de mínimos quadrados ordinais é adequado para a estimação dos coeficientes propostos pelos modelos em estudo.

Para tanto, foi estimada a correlação entre as estimativas dos coeficientes anualmente (ou seja, Corr $[\beta \mathrm{t}, \beta \mathrm{t}-1]=\theta$ ). Os resultados remetem que não há correlação alta entre os erros das variáveis com a distância de dois períodos ( $\mathrm{t}-2$ ). Contudo, em alguns casos foi observa correlação entre os erros das variáveis entre períodos que não ultrapassam 1 ano de diferença (t-1). Tais evidências corroboram os resultados do teste de Durbin-Whatson, e também viabilizam a utilização da regressão de análise em painel pelo modelo de estimação dos mínimos quadrados ordinais.

A Tabela 2 demonstra os resultados da análise de dados em painel com empresas de baixa tecnologia, segregadas por país, com relação à variável dependente preço da ação.

Observa-se, com base na Tabela 2, que os modelos foram significantes ao nível de $5 \%$, em que o primeiro apresentou $\mathrm{R}^{2}$ de 0,5853 , e o segundo $\mathrm{R}^{2}$ 0,5776. Os resultados demonstraram que o valor contábil do patrimônio líquido ajustado (PL-AI), do lucro líquido ajustado (LL-AI), os ativos intangíveis (AI) e o goodwill (GOOD) são relevantes para explicar o preço das ações, tanto nos três meses $\left(\mathrm{P}_{\mathrm{it}+3}\right)$ após o final do trimestre, quanto nos seis meses $\left(\mathrm{P}_{\mathrm{it}+6}\right)$ após publicadas as informações das empresas de baixa tecnologia dos EUA.

A primeira equação que considerou as empresas de baixa tecnologia do Brasil demonstrou-se significativa ao nível de $5 \%$, com $\mathrm{R}^{2}$ de 0,9508 , ou seja, há um poder de explicação em relação ao preço da ação três meses 
após o final do trimestre de $95,08 \%$. Os resultados indicaram que o valor contábil do patrimônio líquido ajustado (PL-AI), os ativos intangíveis (AI) e o goodwill (GOOD) são relevantes para explicar o preço das ações três meses $\left(\mathrm{P}_{\mathrm{it}+3}\right)$ após o final do trimestre nas empresas brasileiras.

Tabela 2 Regressão de dados em painel com empresas de baixa tecnologia -

\section{Preço da ação}

\begin{tabular}{|c|c|c|c|c|c|c|c|c|}
\hline \multirow[t]{3}{*}{ Variáveis } & \multirow{2}{*}{\multicolumn{2}{|c|}{$\begin{array}{r}\text { Efeitos Fixos } \\
\text { (1) Estados } \\
\text { Unidos } \\
\text { Preço da ação } \\
3 \text { meses }\end{array}$}} & \multirow{2}{*}{\multicolumn{2}{|c|}{\begin{tabular}{|r|} 
Efeitos Fixos \\
(2) Estados \\
Unidos \\
Preço da ação \\
6 meses
\end{tabular}}} & \multirow{2}{*}{\multicolumn{2}{|c|}{$\begin{array}{r}\text { Pols } \\
\text { (1) Brasil } \\
\\
\text { Preço da ação } \\
3 \text { meses }\end{array}$}} & \multirow{2}{*}{\multicolumn{2}{|c|}{$\begin{array}{r}\text { Efeitos Fixos } \\
\text { (2) Brasil } \\
\text { Preço da ação } \\
6 \text { meses }\end{array}$}} \\
\hline & & & & & & & & \\
\hline & Coefic. & Sig. & Coefic. & Sig. & Coefic. & Sig. & Coefic. & Sig. \\
\hline PL-Al & 0,716 & ${ }^{*} 0,000$ & 0,779 & ${ }^{*} 0,000$ & 0,942 & ${ }^{*} 0,000$ & 0,802 & $* 0,000$ \\
\hline LL-AI & 0,114 & ${ }^{*} 0,000$ & 0,059 & ${ }^{*} 0,000$ & 0,008 & 0,122 & 0,003 & 0,613 \\
\hline $\mathrm{Al}$ & 0,719 & ${ }^{*} 0,000$ & 0,467 & ${ }^{*} 0,000$ & 0,945 & ${ }^{*} 0,000$ & 0,800 & ${ }^{*} 0,000$ \\
\hline GOOD & 1,446 & ${ }^{*} 0,000$ & 1,561 & ${ }^{*} 0,000$ & 1,899 & ${ }^{*} 0,000$ & 1,667 & ${ }^{*} 0,000$ \\
\hline _Constante & 18,963 & ${ }^{*} 0,000$ & 23,26 & ${ }^{*} 0,000$ & 1,145 & ${ }^{*} 0,000$ & 4,199 & ${ }^{*} 0,000$ \\
\hline R Within & & 0,5853 & & 0,5776 & & $-\cdots$ & & 0,6961 \\
\hline $\mathrm{R}$ Between & & 0,8946 & & 0,8936 & & 0,9508 & & 0,9798 \\
\hline R Overall & & 0,8379 & & 0,8379 & & $-\cdots$ & & 0,9053 \\
\hline Teste F & & ${ }^{*} 0,0000$ & & ${ }^{*} 0,0000$ & & ${ }^{*} 0,0000$ & & ${ }^{*} 0,0000$ \\
\hline Breusch-Pagan & ${ }^{*} \operatorname{Sig} x$ & ' 20,0000 & ${ }^{*} \operatorname{Sig} X$ & 攵 0,0000 & Sig & $x^{2} 0,3190$ & ${ }^{*} \operatorname{Sig} x$ & $x^{2} 0,0000$ \\
\hline Teste de Chow & ${ }^{*}$ Sig. & $\mathrm{F} 0,0000$ & ${ }^{*}$ Sig. & $\mathrm{F} 0,0000$ & & $F 0,0616$ & ${ }^{*}$ Sig. & $\mathrm{F} 0,0000$ \\
\hline Teste de Hausman & ${ }^{*}$ Sig. $x$ & $k^{2} 0,0000$ & ${ }^{*}$ Sig. $X$ & $\left\langle^{2} 0,0000\right.$ & & g. $X^{2}-\cdots$ & ${ }^{*}$ Sig. $X$ & $x^{2} 0,0000$ \\
\hline $\mathrm{N}$ & & 30.144 & & 30.144 & & 1.808 & & 1.808 \\
\hline
\end{tabular}

Fonte: Dados da pesquisa.

* Significante ao nível de 5\%.

(1) Equação 1 com empresas de baixa tecnologia; (2) Equação 2 com empresas de baixa tecnologia.

A segunda equação com empresas de baixa tecnologia do Brasil demonstrou ser significante em $5 \%$ e com poder de explicação de $69,61 \%$. Os resultados encontrados indicaram que o patrimônio líquido ajustado (PL-AI), os ativos intangíveis (AI) e o goodwill (GOOD) foram relevantes para explicar o preço das ações seis meses $\left(\mathrm{P}_{\mathrm{it}+6}\right)$ após o final do trimestre nas empresas brasileiras de baixa tecnologia.

Desse modo, pode-se inferir que no Brasil, ao contrário dos EUA, o valor contábil do lucro líquido não é relevante para explicar o preço da 
ação. Em ambos os países, mesmo em empresas com alta tangibilidade (grande quantidade de ativos tangíveis), os ativos intangíveis são relevantes para explicar o preço das ações. Além disso, outra constatação é que no caso das empresas brasileiras o poder explicativo das variáveis tem diminuído com o passar do tempo, visto que o poder explicativo do preço da ação, seis meses depois de publicadas as informações, é menor do que o poder explicativo do preço da ação três meses depois de divulgadas as demonstrações. Enquanto que nas empresas americanas o $\mathrm{R}^{2}$ dos dois modelos é semelhante.

Apresentam-se na Tabela 3 a regressão de dados em painel com empresas de baixa tecnologia, segregadas por país, com relação àa variável dependente retorno da ação.

Tabela 3 Regressão de dados em painel com empresas de baixa tecnologia Retorno da ação

\begin{tabular}{|c|c|c|c|c|c|c|c|c|}
\hline \multirow[t]{3}{*}{ Variáveis } & \multirow{2}{*}{\multicolumn{2}{|c|}{$\begin{array}{r}\text { Pols } \\
\text { (3) Estados } \\
\text { Unidos } \\
\text { Retorno da ação } \\
3 \text { meses }\end{array}$}} & \multicolumn{2}{|c|}{ Efeitos Fixos } & \multicolumn{2}{|c|}{ Efeitos Fixos } & \multicolumn{2}{|c|}{ Efeitos Fixos } \\
\hline & & & \multicolumn{2}{|c|}{$\begin{array}{r}\text { (4) Estados } \\
\text { Unidos } \\
\text { Retorno da ação } \\
6 \text { meses }\end{array}$} & \multicolumn{2}{|c|}{$\begin{array}{r}\text { (3) Brasil } \\
\text { Retorno da ação } \\
3 \text { meses }\end{array}$} & \multicolumn{2}{|c|}{$\begin{array}{r}\text { (4) Brasil } \\
\text { Retorno da ação } \\
6 \text { meses }\end{array}$} \\
\hline & Coefic. & Sig. & Coefic. & Sig. & Coefic. & Sig. & Coefic. & Sig. \\
\hline PL-AI & 9,080 & 0,415 & $-0,0002$ & $0,000^{*}$ & $-0,0001$ & 0,144 & $-0,0001$ & 0,734 \\
\hline LL-AI & 0,001 & ${ }^{*} 0,000$ & $-0,0001$ & ${ }^{*} 0,002$ & 0,0001 & 0,211 & $-0,0001$ & 0,493 \\
\hline $\mathrm{Al}$ & $-0,001$ & ${ }^{*} 0,009$ & $-0,0001$ & ${ }^{*} 0,000$ & $-0,0001$ & 0,218 & $-2,8200$ & 0,996 \\
\hline GOOD & 0,001 & 0,265 & $-0,0001$ & ${ }^{*} 0,000$ & $-0,0025$ & ${ }^{*} 0,001$ & $-0,0016$ & ${ }^{*} 0,017$ \\
\hline _Constante & 0,042 & 0,000 & 0,0589 & ${ }^{*} 0,000$ & 0,0094 & 0,423 & $-0,0094$ & 0,413 \\
\hline R Within & & --- & & 0,0056 & & 0,0141 & & 0,0132 \\
\hline $\mathrm{R}$ Between & & ---- & & 0,0052 & & 0,0354 & & 0,0360 \\
\hline R Overall & & --- & & 0,0001 & & 0,0001 & & 0,0001 \\
\hline R-Squared & & 0,0008 & & & & & & \\
\hline Teste F & & ${ }^{*} 0,0000$ & & ${ }^{*} 0,0000$ & & ${ }^{*} 0,0002$ & & ${ }^{*} 0,0003$ \\
\hline Breusch-Pagan & *Sig & ${ }^{2} 1,000$ & ${ }^{*} \operatorname{Sig} X$ & $2^{2} 0,0012$ & Sig & 0.0790 & ${ }^{*} \mathrm{Sig}$ & $2^{2} 0,0029$ \\
\hline Teste de Chow & *Sig. & $F 0,1364$ & *Sig. & $F 0,0000$ & *Sig. & $F 0,0071$ & ${ }^{*}$ Sig. & $F 0,0002$ \\
\hline Teste de Hausman & & & ${ }^{*}$ Sig. $X$ & ${ }^{2} 0,0000$ & & $X^{2}-\cdots--$ & ${ }^{*} \mathrm{Sig}$ & $2^{2} 0,0001$ \\
\hline $\mathrm{N}$ & & 28.260 & & 28.260 & & 1.695 & & 1.695 \\
\hline
\end{tabular}

Fonte: Dados da pesquisa.

* Significante ao nível de 5\%.

(3) Equação 3 com empresas de baixa tecnologia; (4) Equação 4 com empresas de baixa tecnologia. 
Verifica-se, com base na Tabela 3, que houve redução da quantidade de observações desses modelos em relação aos modelos do preço da ação, devido ao cálculo do retorno da ação, em que foi preciso considerar o preço da ação do período anterior versus o preço da ação do período atual e, portanto, as observações do primeiro trimestre de 2010 tiveram que ser suprimidas, pois compuseram as informações relativas ao retorno da ação do segundo trimestre de 2010.

Em relação aos achados, observou-se baixo poder de explicação para os modelos propostos de retorno da ação, em que os baixos coeficientes da regressão apontaram para a conclusão de que a relevância das informações de ativos intangíveis não impactou no retorno da ação para as empresas de baixa tecnologia de ambos os países, Brasil e EUA.

Tabela 4 Regressão de dados em painel com empresas de alta tecnologia Preço da ação

\begin{tabular}{|c|c|c|c|c|c|c|c|c|}
\hline \multirow[t]{3}{*}{ Variáveis } & \multirow{2}{*}{\multicolumn{2}{|c|}{$\begin{array}{r}\text { Pols } \\
\text { (1) Estados } \\
\text { Unidos } \\
\text { Preço da ação } \\
3 \text { meses }\end{array}$}} & \multirow{2}{*}{\multicolumn{2}{|c|}{$\begin{array}{r}\text { Efeitos Fixos } \\
(2) \text { Estados } \\
\text { Unidos } \\
\text { Preço da ação } \\
6 \text { meses }\end{array}$}} & \multirow{2}{*}{\multicolumn{2}{|c|}{$\begin{array}{r}\text { Efeitos Fixos } \\
\text { (1) Brasil } \\
\text { Preço da ação } \\
3 \text { meses }\end{array}$}} & \multicolumn{2}{|c|}{ Efeitos Fixos } \\
\hline & & & & & & & \multicolumn{2}{|c|}{$\begin{array}{r}\text { (2) Brasil } \\
\text { Preço da ação } \\
6 \text { meses }\end{array}$} \\
\hline & Coefic. & Sig. & Coefic. & Sig. & Coefic. & Sig. & Coefic. & Sig. \\
\hline PL-AI & 1,089 & $* 0,000$ & 0,982 & ${ }^{*} 0,000$ & 0,719 & ${ }^{*} 0,000$ & 0,490 & ${ }^{*} 0,000$ \\
\hline LL-Al & 0,168 & ${ }^{*} 0,027$ & $-0,012$ & 0,243 & $-0,007$ & 0,704 & $-0,031$ & 0,222 \\
\hline Al & 1,080 & $* 0,000$ & 1,309 & ${ }^{*} 0,000$ & 0,747 & ${ }^{*} 0,000$ & 0,496 & ${ }^{*} 0,000$ \\
\hline GOOD & 2,124 & $*^{*} 0,000$ & 1,880 & ${ }^{*} 0,000$ & 1,433 & ${ }^{*} 0,000$ & 0,958 & ${ }^{*} 0,000$ \\
\hline _Constante & $-0,197$ & 0,285 & 3,943 & ${ }^{*} 0,000$ & 4,161 & ${ }^{*} 0,002$ & 8,122 & ${ }^{*} 0,000$ \\
\hline R Within & & $-\cdots-$ & & 0,7132 & & 0,6343 & & 0,3323 \\
\hline $\mathrm{R}$ Between & & 0,9670 & & 0,9875 & & 0,9993 & & 0,9963 \\
\hline R Overall & & --- & & 0,9390 & & 0,9749 & & 0,9475 \\
\hline Teste F & & ${ }^{*} 0,0000$ & & ${ }^{*} 0,0000$ & & ${ }^{*} 0,0000$ & & ${ }^{*} 0,0000$ \\
\hline Breusch-Pagan & $\operatorname{Sig} X$ & $\left\langle^{2} 1,0000\right.$ & $\operatorname{Sig} X$ & 21,0000 & $\operatorname{Sig} X$ & $2^{2} 1,0000$ & $\operatorname{Sig} X$ & $\left\langle{ }^{2} 1,0000\right.$ \\
\hline Teste de Chow & Sig. & $F 0,4364$ & *Sig. & $F 0,0000$ & ${ }^{*}$ Sig. & $F 0,0020$ & *Sig. & $F 0,0000$ \\
\hline Teste de Hausman & & ig. X² --- & & ig. $X^{2}---$ & & Sig. X² --- & & Sig. $X^{2}---$ \\
\hline $\mathrm{N}$ & & 5.504 & & 5.504 & & 80 & & 80 \\
\hline
\end{tabular}

Fonte: Dados da pesquisa.

* Significante ao nível de 5\%.

(1) Equação 1 com empresas de alta tecnologia; (2) Equação 2 com empresas de alta tecnologia. 
A Tabela 4 mostra a regressão de dados em painel com empresas de alta tecnologia, segregadas por país, com relação à variável dependente preço da ação.

Verifica-se na Tabela 4 que a primeira equação, com empresas de alta tecnologia dos Estados Unidos, foi significante ao nível de 5\%, com $\mathrm{R}^{2}$ de 0,9670. Os resultados indicaram que o valor contábil do patrimônio líquido ajustado (PL-AI), o valor contábil do lucro líquido ajustado (LL_AIAI), os ativos intangíveis (AI) e o goodwill (GOOD) são relevantes para explicar o preço das ações três meses $\left(\mathrm{P}_{\mathrm{it}+3}\right)$ após o final do trimestre nas empresas analisadas.

A segunda equação com empresas de alta tecnologia dos EUA demonstrou ser significante ao nível de $5 \%$ e com explicação de $71,32 \%$. Os achados indicam que o patrimônio líquido ajustado (PL-AI), os ativos intangíveis (AI) e o goodwill (GOOD) foram relevantes para explicar o preço das ações seis meses $\left(\mathrm{P}_{\mathrm{it+6}}\right)$ após a publicação das demonstrações contábeis das empresas investigadas. Contudo, o lucro líquido ajustado (LL-AI) perde o poder explicativo ao longo do tempo, ao considerar que não se apresentou significativo para explicar o preço das ações seis meses depois de publicados os demonstrativos.

As equações 1 e 2 com empresas de alta tecnologia do Brasil apresentaram-se significativas ao nível de $5 \%$, com $\mathrm{R}^{2}$ de $63,43 \%$ e $33,23 \%$, respectivamente. Os resultados indicaram que o valor contábil do patrimônio líquido ajustado (PL-AI), os ativos intangíveis (AI) e o goodwill (GOOD) são relevantes para explicar o preço das ações, tanto três meses $\left(\mathrm{P}_{\mathrm{it}+3}\right)$ quanto seis meses $\left(\mathrm{P}_{\mathrm{it}+6}\right)$ após o final do trimestre nas empresas brasileiras de alta tecnologia.

Apresentam-se na tabela 5 a regressão de dados em painel com empresas de alta tecnologia, segregadas por país, com relação à variável dependente retorno da ação.

Verifica-se na Tabela 5 que as equação 3 e 4 que consideraram empresas de alta tecnologia dos EUA e do Brasil demonstraram ser significantes, entretanto, conforme os demais modelos, apresentam baixo poder de explicação, bem como coeficientes das variáveis explicativas pouco representativos. Dessa forma, considerou-se que o retorno da ação não é influenciado de forma relevante pelas informações contábeis analisadas nas empresas de alta tecnologia dos EUA e do Brasil.

De modo geral, os achados observados nas análises anteriores demonstraram evidências sobre a diferença no reconhecimento das contas contábeis (oriundas da FASB e IASB) utilizadas, que impactam na relevância 
da informação contábil, especialmente em se tratando do lucro líquido ajustado (LL-AI). Observou-se que o lucro líquido ajustado apresenta relevância de informação em empresas dos EUA e que no Brasil, ao contrário, tal influência não demonstrou ser significativa. Entretanto, não se pode afirmar que tal ocorrido seja em decorrência somente das normas contábeis, necessitando de investigações para o aprofundamento de tal indução. Além disso, a recente adoção das normas IFRS pelas empresas brasileiras pode ter interferido nos achados, visto que tais organizações ainda podem estar em fase de aprendizado sobre reconhecimento de ativos intangíveis.

Tabela 5 Regressão de dados em painel com empresas de alta tecnologia -

Retorno da ação

\begin{tabular}{|c|c|c|c|c|c|c|c|c|}
\hline \multirow[t]{3}{*}{ Variáveis } & \multirow{2}{*}{\multicolumn{2}{|c|}{$\begin{array}{r}\text { Pols } \\
\text { (3) Estados } \\
\text { Unidos } \\
\text { Retorno da ação } \\
3 \text { meses }\end{array}$}} & \multirow{2}{*}{\multicolumn{2}{|c|}{$\begin{array}{r}\text { Efeitos Fixos } \\
\text { (4) Estados } \\
\text { Unidos } \\
\text { Retorno da ação } \\
6 \text { meses }\end{array}$}} & \multirow{2}{*}{\multicolumn{2}{|c|}{$\begin{array}{r}\text { Efeitos Fixos } \\
(3) \text { Brasil } \\
\\
\text { Retorno da ação } \\
3 \text { meses }\end{array}$}} & \multirow{2}{*}{\multicolumn{2}{|c|}{$\begin{array}{r}\text { Efeitos Fixos } \\
(4) \text { Brasil } \\
\\
\text { Retorno da ação } \\
6 \text { meses }\end{array}$}} \\
\hline & & & & & & & & \\
\hline & Coefic. & Sig. & Coefic. & Sig. & Coefic. & Sig. & Coefic. & Sig. \\
\hline PL-Al & $-0,0026$ & $* 0,000$ & $-0,0038$ & ${ }^{*} 0,000$ & $-0,0084$ & 0,159 & $-0,0061$ & 0,398 \\
\hline LL-Al & 0,0003 & ${ }^{*} 0,026$ & $-0,0001$ & ${ }^{*} 0,010$ & $-0,0001$ & 0,527 & $-0,0012$ & 0,423 \\
\hline $\mathrm{Al}$ & 0,0001 & 0,483 & 0,0001 & 0,508 & $-0,0104$ & ${ }^{*} 0,031$ & $-0,0086$ & 0,137 \\
\hline GOOD & $-0,0036$ & ${ }^{*} 0,000$ & $-0,0040$ & ${ }^{*} 0,000$ & $-0,0204$ & 0,061 & $-0,0173$ & 0,187 \\
\hline _Constante & 0,0781 & ${ }^{*} 0,000$ & 0,0733 & ${ }^{*} 0,000$ & 0,1067 & 0,2333 & 0,0071 & 0,506 \\
\hline R Within & & 0,0208 & & 0,0276 & & 0,0799 & & 0,0548 \\
\hline $\mathrm{R}$ Between & & 0,0485 & & 0,0637 & & 0,2566 & & 0,1001 \\
\hline R Overall & & 0,0001 & & 0,0001 & & 0,0149 & & 0,0026 \\
\hline Teste F & & $* 0,0000$ & & $* 0,0000$ & & *0,2332 & & *0,4370 \\
\hline Breusch-Pagan & ${ }^{*} \operatorname{Sig} x$ & $\left\langle^{2} 1,0000\right.$ & ${ }^{*} \operatorname{Sig} x$ & $\gamma^{2} 1,0000$ & $\operatorname{sig} x$ & ${ }^{2} 1,0000$ & $\left.{ }^{*} \operatorname{Sig}\right\rangle$ & ${ }^{2} 1,0000$ \\
\hline Teste de Chow & ${ }^{*}$ Sig. & F 0,0332 & ${ }^{*}$ Sig. & $F 0,0000$ & ${ }^{*}$ Sig. & $=0,0043$ & ${ }^{*}$ Sig. & $=0,0069$ \\
\hline Teste de Hausman & & g. $X^{2}-\cdots--$ & & g. $X^{2}-\cdots--$ & & $x^{2}-\ldots-$ & & s. $X^{2}-\ldots$ \\
\hline $\mathrm{N}$ & & 5.160 & & 5.160 & & 75 & & 75 \\
\hline
\end{tabular}

Fonte: Dados da pesquisa.

* Significante ao nível de 5\%.

(3) Equação 3 com empresas de baixa tecnologia; (4) Equação 4 com empresas de baixa tecnologia.

As contas como patrimônio líquido ajustado (PL-AI), ativo intangível (AI) e goodwill (GOOD) apresentaram relevância de informação semelhante em ambas às nações. Além disso, observou-se que tanto nas empresas bra- 
sileiras e americanas de alta tecnologia o poder explicativo das variáveis diminui com o passar do tempo, tendo em vista a explicação dos modelos.

As evidências encontradas no cenário brasileiro aproximam-se do estudo de Amir e Lev (1996), os quais constataram que variáveis contábeis como lucro líquido não possuem poder explicativo significativo nas empresas intangíveis intensivas. Nos resultados encontrados na presente pesquisa, o lucro líquido (ajustado pelas despesas de amortização e perdas com intangíveis) também não apresentou value relevance nas empresas brasileiras com baixa e alta tecnologia.

Porém, no cenário americano, todas as variáveis foram significativas para explicar o comportamento no preço das ações. Este resultado corrobora os estudos de Lopes (2002) e Rezende (2005), em que o patrimônio e o lucro líquido possuem poder explicativo significativo em empresas brasileiras; e no cenário de empresas americanas, é corroborado por Kallapur e Kwan (2004), em relação à relevância da informação do lucro líquido e patrimônio líquido.

Quanto ao ativo intangível, esse se apresentou relevante em todos os modelos em ambos os países, o que discorda ao estudo de Rezende (2005), cujos resultados apontam efeito inverso ao esperado (efeito negativo) do ativo diferido. Tal discrepância pode ter sido ocasionada pela forma diferenciada de mensuração da antiga conta ativo diferido, com a atual conta ativo intangível. Todavia, esse resultado corrobora aos achados encontrados por Silva, Souza e Klann (2015), os quais também observaram no cenário de empresas brasileiras que informações sobre ativos intangíveis são relevantes para o mercado de capitais e inclusive contribuem para o aumento do poder informacional das informações de patrimônio e lucro líquido.

Os resultados aqui evidenciados concordam com os dos estudos de Vafaei et al. (2011) e Oliveira et al. (2010), que ao testarem a relevância dos ativos intangíveis reconhecidos nas empresas, constataram que esses são significativamente associados ao preço das ações, impactando o mercado de capitais, principalmente em segmentos não tracionais (tecnológicos) como observado por Vafaei et al. (2011). Na presente pesquisa, os ativos intangíveis, inclusive o goodwill, também se mostraram relevantes nas empresas de baixa e de alta tecnologia brasileiras e americanas.

Em uma análise comparativa das empresas de baixa e alta tecnologia de ambos os países, é possível inferir que não foram encontradas diferenças significativas em relação à relevância da informação contábil, principal- 
mente dos ativos intangíveis sobre o preço das ações, verificando-se somente discrepância da relevância do lucro líquido ajustado.

Averígua-se com maior robustez as tendências apontadas sobre a comparação entre empresas de alta e baixa tecnologia dos EUA e do Brasil. Foram efetuados testes adicionais que são demonstrados no tópico a seguir.

Com o intuito de ampliar e demonstrar uma visão diferenciada dos resultados até aqui encontrados, realizaram-se testes de robustez, os quais são apresentados na Tabela 6. Foram juntadas as amostras das empresas de alta e baixa tecnologia do Brasil e dos EUA e, para capturar as informações almejadas, incorporaram-se variáveis dummy para observar o comportamento das empresas de alta e baixa tecnologia, e também das empresas de cada país, sobre o preço e retorno da ação. Além disso, adicionaram-se variáveis de interação entre ativo intangível e goodwill com a variável dummy de tecnologia, buscando capturar o efeito das empresas de alta tecnologia com reconhecimentos de ativos intangíveis e goodwill sobre o preço e retorno da ação.

A Tabela 6 demonstra as regressões de dados em painel dos modelos agregados.

De acordo com a Tabela 6, os testes remeteram àutilização da regressão de dados em painel pelo modelo de efeito fixo para as equações 5 , 6,7 e 8 . Entretanto, os modelos de efeitos fixos omitiram variáveis explicativas (dummies), então, fez-se uso do modelo de efeitos aleatórios, pois esses não omitiram as variáveis dummies, que eram necessárias para a consecução da análise.

Os resultados demonstraram que o PL e LL ajustados, o ativo intangível e o goodwill apresentaram-se como relevantes para o aumento no preço das ações. Além disso, as empresas de alta tecnologia apresentaram menor preço da ação, em comparação com empresas de baixa tecnologia, resultado que pode ser decorrente da diferença amostral entre esses tipos de empresas, em que a amostra de empresas de alta tecnologia foi inferior. Por fim, constatou-se que as empresas localizadas nos EUA possuem maior preço da ação, em comparação com as empresas brasileiras.

Os achados relacionados às variáveis dummys de empresas de tecnologia interagindo com ativos intangíveis e goodwill demonstraram que as empresas de tecnologia com maior proporção de divulgação de ativos intangíveis e goodwill apresentaram maior relevância de informação para o aumento no preço das ações. Sugere-se que empresas de tecnologia que reconhecem adequadamente seus ativos intangíveis e/ou goodwill tendem a proporcionar 
aumento no preço das ações. Por fim, o teste de robustez para os modelos de retorno da ação comprovaram os resultados obtidos nos modelos anteriores em relação ao retorno da ação, os quais evidenciaram que tal modelo não é impactado de forma relevante pelas informações contábeis analisadas.

Tabela 6 Regressão de dados em painel dos modelos agregados

\begin{tabular}{|c|c|c|c|c|c|c|c|c|}
\hline \multirow[t]{3}{*}{ Variáveis } & \multirow{2}{*}{\multicolumn{2}{|c|}{\begin{tabular}{|r} 
Efeitos Aleatórios \\
(5) Preço da ação \\
3 meses
\end{tabular}}} & \multirow{2}{*}{\multicolumn{2}{|c|}{\begin{tabular}{|r} 
Efeitos Aleatórios \\
(6) Preço da ação \\
6 meses
\end{tabular}}} & \multirow{2}{*}{\multicolumn{2}{|c|}{\begin{tabular}{|r} 
Efeitos Aleatórios \\
(7) Preço da ação \\
3 meses
\end{tabular}}} & \multirow{2}{*}{\multicolumn{2}{|c|}{\begin{tabular}{|r} 
Efeitos Aleatórios \\
(8) Preço da ação \\
6 meses
\end{tabular}}} \\
\hline & & & & & & & & \\
\hline & Coefic. & Sig. & Coefic. & Sig. & Coefic. & Sig. & Coefic. & Sig. \\
\hline PL-Al & 0,7832 & $* 0,000$ & 0,832 & ${ }^{*} 0,000$ & 6,4000 & 0,554 & 1,3010 & 0,907 \\
\hline LL-Al & 0,1258 & ${ }^{*} 0,000$ & 0,086 & ${ }^{*} 0,000$ & 0,0001 & ${ }^{*} 0,000$ & 0,0001 & 0,117 \\
\hline Al & 0,7332 & ${ }^{*} 0,000$ & 0,565 & ${ }^{*} 0,000$ & $-0,0001$ & ${ }^{*} 0,009$ & $-0,0002$ & ${ }^{*} 0,000$ \\
\hline GOOD & 1,5773 & $* 0,000$ & 1,670 & ${ }^{*} 0,000$ & 0,0001 & 0,353 & 4,6124 & 0,835 \\
\hline DummyTecn & $-11,481$ & ${ }^{*} 0,000$ & $-13,96$ & $* 0,000$ & $-0,0041$ & 0,321 & $-0,0098$ & ${ }^{*} 0,023$ \\
\hline DummyTec*AI & 0,4953 & ${ }^{*} 0,000$ & 0,737 & ${ }^{*} 0,000$ & 0,0003 & 0,217 & 0,0037 & 0,135 \\
\hline DummyTec*G0OD & 0,0702 & ${ }^{*} 0,000$ & 0,027 & 0,099 & $-0,0001$ & 0,579 & $-0,0002$ & 0,751 \\
\hline DummyPaís & $-11,059$ & ${ }^{*} 0,003$ & $-12,95$ & ${ }^{*} 0,001$ & $-0,0478$ & ${ }^{*} 0,000$ & $-0,0525$ & ${ }^{*} 0,000$ \\
\hline _Constante & 15,957 & ${ }^{*} 0,000$ & 23,26 & ${ }^{*} 0,000$ & 0,0423 & ${ }^{*} 0,000$ & 0,0418 & ${ }^{*} 0,000$ \\
\hline R Within & & 0,5923 & & 0,5796 & & 0,0001 & & 0,0008 \\
\hline $\mathrm{R}$ Between & & 0,9003 & & 0,8977 & & 0,0441 & & 0,0331 \\
\hline R Overall & & 0,8450 & & 0,8419 & & 0,0029 & & 0,0031 \\
\hline Teste F & & $* 0,0000$ & & ${ }^{*} 0,0000$ & & *0,0000 & & ${ }^{*} 0,0000$ \\
\hline Breusch-Pagan & ${ }^{*} \operatorname{Sig} X$ & 20,0000 & ${ }^{*} \operatorname{Sig} X$ & ${ }^{2} 0,0000$ & $\operatorname{Sig} X$ & $2^{2} 1,0000$ & *Si & $x^{2} 0,0017$ \\
\hline Teste de Chow & ${ }^{*}$ Sig. & $\mathrm{F} 0,0000$ & ${ }^{*}$ Sig. & $F 0,0000$ & Sig. & F 0,0231 & ${ }^{*} \mathrm{Si}$ & $F 0,0000$ \\
\hline Teste de Hausman & ${ }^{*}$ Sig. & ${ }^{2} 0,0000$ & ${ }^{*}$ Sig. $X$ & ${ }^{2} 0,0000$ & & $X^{2}-\cdots--$ & ${ }^{*} \mathrm{Sig}$ & 20,0000 \\
\hline $\mathrm{N}$ & & 37.536 & & 37.536 & & 35.190 & & 35.190 \\
\hline
\end{tabular}

Fonte: Dados da pesquisa.

* Significante ao nível de 5\%.

(5) Equação 5; (6) Equação 6; (7) Equação 7; (8) Equação 8.

\section{Considerações finais}

A presente pesquisa teve por objetivo analisar a relevância dos ativos intangíveis em empresas de alta e baixa tecnologia dos EUA e do Brasil. Em relação aos resultados das empresas dos EUA, constatou-se que o valor 
contábil do patrimônio líquido ajustado, o valor contábil do lucro líquido ajustado, os ativos intangíveis e o goodwill são relevantes para explicar o preço das ações de empresas de baixa e alta tecnologia. Apenas o lucro líquido ajustado não demonstrou influência significativa quando analisado o preço das ações seis meses após o encerramento do trimestre nas empresas com alta tecnologia. Conclui-se que o lucro líquido perde poder explicado com o passar do tempo no mercado americano nas empresas com alta tecnologia.

Em relação à relevância da informação em empresas brasileiras, observou-se que o valor contábil do patrimônio líquido ajustado, os ativos intangíveis e o goodwill são relevantes para explicar o preço das ações (três meses e seis meses após o final do trimestre) em empresas brasileiras com baixa e alta tecnologia. Nas empresas brasileiras, ao contrário das americanas, o valor contábil do lucro líquido ajustado não é relevante para explicar o preço das ações.

De maneira geral, constatou-se também que, em ambos os países, mesmo em empresas com alta tangibilidade (baixa tecnologia), os ativos intangíveis são relevantes para explicar o preço das ações. Os resultados demonstraram que as diferenças entre as normas contábeis adotadas (US GAAP e IFRS), o fato de ser um país emergente (Brasil) ou desenvolvido (EUA), além de outras possíveis diferenças entre os dois grupos de empresas analisadas (brasileiras e norte americanas), como tamanho do mercado acionário, tamanho das empresas, diferenças culturais dos investidores, nível de transparência das informações, mecanismos de governança corporativa, não analisados diretamente neste estudo, não impactaram o value relevance da informação contábil em se tratando da mensuração dos ativos intangíveis de empresas com alta tangibilidade.

De maneira prática, o estudo tem a contribuição de inferir que além das informações contábeis fundamentais, como patrimônio líquido e lucro líquido (Ohlson, 1995), os ativos intangíveis e o goodwill também precisam ser considerados pelos analistas de mercado, visto o impacto positivo no preço das ações em economia desenvolvida, em desenvolvimento, e entre países que adotam diferentes normas de contabilidade.

Conclui-se, assim, que os ativos intangíveis são relevantes não somente para as empresas com alta concentração de intangíveis (alta tecnologia), como as de tecnologia e telecomunicações, mas também são relevantes para as empresas de baixa tecnologia. A obrigatoriedade de reconhecimen- 
to de determinados ativos intangíveis previstos em normas contábeis nacionais e internacionais pode contribuir para a melhoria das informações contábeis, tornando-as mais relevantes para a tomada de decisão de diversos agentes econômicos.

Somado a isso, fatores adicionais foram observados no teste de robustez, evidenciando que empresas de alta tecnologia, quando possuíam ativos intangíveis e goodwill, apresentaram maior preço da ação e, portanto, a relevância dos ativos intangíveis nas empresas de tecnologia influencia no aumento do preço da ação.

Quando considerada a relevância da informação dos ativos intangíveis no retorno da ação, concluiu-se que não há impacto relevante das informações contábeis relacionadas aos ativos intangíveis, goodwill, patrimônio líquido e lucro líquidos ajustados sobre o retorno das ações em empresas dos EUA e do Brasil com alta ou baixa tecnologia.

Como limitação do estudo, tem-se a não inclusão de variáveis de mercado que poderiam ter interferido no preço e ou retorno da ação, entretanto, como o objetivo do estudo era o de analisar o impacto que informações contábeis geram nas ações, acredita-se que tal limitação não compromete a pesquisa. Sugere-se como pesquisas futuras a verificação da influência do ativo intangível em demais propriedades da informação contábil, a fim de verificar efeitos positivos ou negativos na qualidade da informação contábil como um todo, contribuindo com a atual pesquisa, em que se verificou efeito positivo de intangíveis na propriedade relevância da informação principalmente em empresas de tecnologia.

\section{Referências}

ABOODY, D.; LEV, B. The value relevance of intangibles: the case of software capitalization. Journal of Accounting Research, 161-191, 1998.

ALBERTIN, A. L. Valor estratégico dos projetos de tecnologia de informação. Revista de Administração de Empresas, 41 (3), 42-50, 2001.

AMIR, E.; LEV, B. Value-relevance of nonfinancial information: The wireless communications industry. Journal of Accounting and Economics, 22 (1), 3-30, 1996.

BAKER, C. R.; BARBU, E. M. Trends in research on international accounting harmonization. The International Journal of Accounting, 42 (3), 272-304, 2007.

BALL, R.; BROWN, P. An empirical evaluation of accounting income numbers. Journal of Accounting Research, 159-178, 1968. 
Barras, R. Towards a theory of innovation in services. Research Policy, 15 (4), 161-173, 1986.

BARTH, M. E.; BEAVER, W. H.; LANDSMAN, W. R. The relevance of the value relevance literature for financial accounting standard setting: another view. Journal of Accounting and Economics, 31 (1), 77-104, 2001.

BARTH, M. E.; LANDSMAN, W. R.; LANG, M. H. International accounting standards and accounting quality. Journal of Accounting Research, 46 (3), 467-498, 2008.

BEATTIE, V. Moving the financial accounting research front forward: the UK contribution. The British Accounting Review, 37 (1), 85-114, 2005.

BEAVER, W. H. The information content of annual earnings announcements. Journal of Accounting Research, 67-92, 1968.

BEAVER, W. H.; CLARKE, R.; WRIGHT, W. F. The association between unsystematic security returns and the magnitude of earnings forecast errors. Journal of Accounting Research, 316-340, 1979.

CARVALHO, M. M.; FIZYSIEZNIG FILHO, J.; MACHADO, S.; RABECHINI-JUNIOR, R. Empresa de base tecnológica brasileira: características distintivas. Anais... In: Simpósio de Gestão da Inovação Tecnológica, 20, 461-74, 1998.

CASSIOLATO, J. E. A economia do conhecimento e as novas políticas industriais e tecnológicas. Informação e globalização na era do conhecimento. Rio de Janeiro: Campus, 164-190, 1999.

CIFTCI, M.; DARROUGH, M.; MASHRUWALA, R. Value Relevance of Accounting Information for Intangible-Intensive Industries and the Impact of Scale: The US Evidence. European Accounting Review, 23 (2), 199-226, 2014.

COLLINS, D. W.; MAYDEW, E. L.; WEISS, I. S. Changes in the value-relevance of earnings and book values over the past forty years. Journal of Accounting and Economics, 24 (1), 39-67, 1997.

CPC 04. Ativo Intangivel. Comitê de Pronunciamentos Contábeis, 2010.

DAMANPOUR, F.; ARAVIND, D. Managerial innovation: Conceptions, processes, and antecedents. Management and Organization Review, 8 (2), 423-454, 2012.

DAMANPOUR, F.; WALKER, R. M.; AVELLANEDA, C. N. Combinative effects of innovation types and organizational performance: A longitudinal study of service organizations. Journal of Management Studies, 46 (4), 650-675, 2009.

DECKER, F.; ENSSLIN, S. R.; REINA, D. R. M.; REINA, D. A relação entre os ativos intangíveis e a rentabilidade das ações: um estudo com empresas listadas no índice Bovespa. REUNA, 18 (4), 75-92, 2013.

DUMONTIER, P.; RAFFOURNIER, B. Accounting and capital markets: a survey of the European evidence. European Accounting Review, 11 (1), 119-151, 2002.

EDVINSSON, L.; MALONE, M. S. Capital intelectual: descobrindo o valor real de sua empresa pela identificação de seus valores internos. São Paulo: Makron Books, 1998.

ERNEST\&YOUNG. US GAAP versus IFRS - The Basics. 2011. Acesso em 02 de janeiro, 2015, de http://www.ey.com/Publication/vwLUAssets/US_GAAP_v_IFRS:_The_BasicsUSGAAP/IFRSDec2011.pdf.

FAMA, E. F.; MACBETH, J. D. Risk, return and equilibrium: Empirical tests. The Journal of 
Political Economy, 81, 607-607, 1973.

FERRO, J. R.; TORKOMIAN, A. L. V. A criação de pequenas empresas de alta tecnologia. Revista de Administração de Empresas, 28(2), 43-50, 1988.

FLEURY, M. T. L.; FLEURY, A. C. C. Alinhando estratégia e competências. RAE-Revista de Administração de Empresas, 44 (1), 44-57, 2004.

FRANCIS, J.; SCHIPPER, K. Have financial statements lost their relevance? Journal of Accounting Research, 319-352, 1999.

GOODWIN, J.; AHMED, K. Longitudinal value relevance of earnings and intangible assets: Evidence from Australian firms. Journal of International Accounting, Auditing and Taxation, 15 (1), 72-91, 2006.

HAMDAN, B. J.; KASPER, G. M. The IT-productivity linkage at the country level for developing economies. In: Proceeding of the Southern Association for Information Systems Conference. Anais... Atlanta, GA. 219-224, 2010.

HENDRIKSEN, E. S.; VAN BREDA, M. F. Teoria da Contabilidade. São Paulo: Atlas, 1999.

HOEGH-KROHN, N. E. J.; KNIVSFLÅ, K. H. Accounting for Intangible Assets in Scandinavia, the UK, the US, and by the IASC: Challenges and a Solution. The International Journal of Accounting, 35 (2), 243-265, 2000.

HUANG, S. M.; OU, C. S., CHEN, C. M.; LIN, B. An empirical study of relationship between IT investment and firm performance: A resource-based perspective. European Journal of Operational Research, 173 (3), 984-999, 2006.

IAS 38 - International Accounting Standards. Intangible Assets. Acessado em 30 de novembro, 2014, de http://www.ifrs.org/IFRSs/IFRS-technical-summaries/Documents/IAS38-English.pdf.

KALLAPUR, S.; Kwan, S. YS. The value relevance and reliability of brand assets recognized by UK firms. The Accounting Review, 79 (1), 151-172, 2004.

KAYO, E. K. A estrutura de capital e o risco das empresas tangivel e intangivel-intensivas: uma contribuição ao estudo da valoração de empresas. 2002. Tese (Doutorado em Administração). Universidade de São Paulo - USP, São Paulo-SC.

LASTRES, H.; CASSIOLATO, J.; LEMOS, C.; MALDONADO, J.; VARGAS, M. Globalização e inovação localizada: experiências de sistemas locais no âmbito do Mercosul e proposições de políticas de C\&T. Nota Técnica, 1, 98, 1998.

LEV, B.; ZAROWIN, P. The Boundaries of Financial Reporting and How to Extend Them (Digest Summary). Journal of Accounting Research, 37 (2), 353-385, 1999.

LEV, B. The boundaries of financial reporting and how to extend them. Working Paper, New York University, New York, NY, 1997.

LEV, B. Intangibles: Management, measurement, and reporting. Brookings Institution Press, 2001.

LIAO, P. C.; LING-CHING CHAN, A.; SENG, J. L. Intellectual capital disclosure and accounting standards. Industrial Management \& Data Systems, 113(8), 1189-1205, 2013.

LOPES, A. B. The value relevance of Brazilian accounting numbers: an empirical investigation. São Paulo, University of São Paulo, Social Science Research Network, SSRN Working 
Paper, v. 311459, 2002.

MARCOVITCH, J.; DOS SANTOS, S. A.; DUTRA, I. Criação de empresas com tecnologias avançadas: as experiências do PACTo/IA-FEA-USP. Revista de Administração da Universidade de São Paulo, 21 (2), 1986.

MORRICONE, S.; ORIANI, R.; SOBRERO, M. The value relevance of intangible assets and the mandatory adoption of IFRS. Available at SSRN 1600725, 2009.

OCDE. Science, Technology and Industry Scoreboard. Paris: OCDE, 2003.

OHLSON, J. A. (1995). Earnings, book values, and dividends in equity valuation. Contemporary Accounting Research, 11 (2), 661-687.

OLIVEIRA, L.; RODRIGUES, L. L.; CRAIG, R. Intangible assets and value relevance: evidence from the Portuguese stock exchange. The British Accounting Review, 42 (4), 241-252, 2010.

PEREZ, M. M.; FAMÁ, R. Ativos intangíveis e o desempenho empresarial. Revista Contabilidade \& Finanças, 17 (40), 7-24, 2006.

REINA, D.; MIGUEL, J. J.; TASCA, T. A.; REINA, D. R. M. Evidenciação do capital intelectual em empresas do setor de tecnologia da informação e do setor de telecomunicações listadas na BM\&FBovespa nos anos de 2007 a 2009. Enfoque: Reflexão Contábil, 30(1), 63-82, 2011.

REZENDE, A. J. A relevância da informação contábil no processo de avaliação de empresas da nova e velha economia - uma análise dos investimentos em ativos intangíveis e seus efeitos sobre value-relevance do lucro e patrimônio líquido. BBR-Brazilian Business Review, 2 (1), 33-52, 2005.

SANTOS, J. L D.; SCHMIDT, P. Avaliação de ativos intangiveis. São Paulo: Atlas, 2002.

SCHNIEDERJANS, M. J.; HAMAKER, J. L.; SCHNIEDERJANS, A. M. Information technology investment: decision-making methodology. World Scientific, 2004.

SILVA, A.; SOUZA, T. R.; KLANN, R. C. A Influência dos Ativos Intangíveis na Relevância da Informação Contábil. XV Congresso USP de Controladoria e Contabilidade, São Paulo, 29 a 31 de julho, 2015.

SONNIER, B. M. Intellectual capital disclosure: high-tech versus traditional sector companies. Journal of Intellectual Capital, 9(4), 705-722, 2008.

TAKAHASHI, T. Sociedade da informação no Brasil: livro verde. Ministério da Ciência e Tecnologia (MCT), 2000.

VAFAEI, A.; TAYLOR, D.; AHMED, K. The value relevance of intellectual capital disclosures. Journal of Intellectual Capital, 12(3), 407-429, 2011.

WEBER, M.; KLEIN, A. Z. Gestão estratégica em empresas de tecnologia da informação: um estudo de caso. Revista Ibero-Americana de Estratégia, 12 (3), 37-65, 2013.

\section{Sobre os autores}

Cristian Baú Dal Magro - cristianbaumagro@gmail.com

Universidade Regional de Blumenau, Blumenau, Santa Catarina.

Alinida Silva - alinicont@gmail.com

Universidade Regional de Blumenau, Blumenau, Santa Catarina. 
Dal Magro, Silva, Padilha \& Klann

Daniel Padilha -danielpadilha06@hotmail.com

Universidade Regional de Blumenau, Blumenau, Santa Catarina.

Roberto Carlos Klann-rklann@furb.br

Universidade Regional de Blumenau, Blumenau, Santa Catarina.

\section{Sobre $o$ artigo}

Recebido em 15 de janeiro de 2016. Aprovado em 03 de junho de 2016. 